\title{
Lateral midfoot pain
}

\author{
Pamela Habib • Joseph S. Yu
}

Published online: 26 June 2014

(C) ISS 2014

\begin{abstract}
Answer
Fracture of an os peroneum.
\end{abstract}

\section{Discussion}

Computed tomography of the patient's left ankle demonstrated two areas of ossification separated by a $2-\mathrm{cm}$ gap along the course of the peroneus longus tendon. Two proximal ossicles were located distal to the peroneal tubercle of the calcaneus and one was inferior to the cuboid. The most proximal ossicle was completely corticated, but the two lower ossicles represented halves of one large ossicle with absence of cortex on the exposed ends of the bone. There was also fluid density within the tendon and edema of the subcutaneous fat adjacent to the common peroneal tendon sheath. This is analogous to the split ossicle sign that may be seen on radiographs. An MRI examination performed 2 days later revealed a complete rupture of the peroneus longus tendon. Attached to each end of the tendon was a portion of the distal ossicle of a bipartite or fused multipartite os peroneum. The patient was taken to the operating room for repair of the torn tendon 13 days later. Surgery confirmed a large amount of fluid in the sheath at the tendinous rupture and two osseous fragments separated by intervening fibrosis.

The case presentation can be found at doi: 10.1007/s00256-014-1933-3

P. Habib

The Ohio State University Wexner Medical Center, 395 West 12th

Avenue, Columbus, OH 43210, USA

J. S. Yu $(\bowtie)$

Department of Radiology, 481 Doan Tower, 395 West 12th Avenue, Columbus, OH 43210, USA

e-mail: joseph.yu@osumc.edu
The os peroneum is usually located at or distal to the calcaneocuboid joint, or within the cuboid tunnel of the cuboid, but can occasionally articulate with the distal lateral calcaneus [1]. It is stabilized by four connective tissue bands that extend to the cuboid, fifth metatarsal base, plantar fascia, and the peroneus brevis tendon [1]. The incidence in the population varies from $5 \%$ to $20 \%$ but the incidence of multipartite ossicles is less clear, since it appears to increase with age owing to the formation of lamellar bone surrounding areas of metaplastic ossification [2].

Diagnosing a fractured os peroneum may be a challenge radiographically. One reason for this is that the fracture can appear either as a division in a solitary ossicle or as diastasis through a multipartite ossicle [3-7]. If the rupture of the tendon occurs away from the ossicle, there can be migration of the ossicle without its fragmentation $[8,9]$. In this situation, prior radiographs can be useful since migration may not be evident if only minimal retraction is present. If a previously solitary ossicle appears multipartite at follow-up, or if a multipartite ossicle demonstrates diastasis between fragments, the diagnosis can be rendered with confidence. Irregularity of the margins of the fragments without sclerosis should raise the index of suspicion for an acute fracture [10]. Ultimately, MRI remains the best modality for further evaluating patients with persistent focal pain from a non-displaced fracture, although bone scintigraphy is also useful when MRI is not available.

The peroneus longus muscle is responsible for pronation, eversion, and plantar flexion of the foot $[8,9]$. The peroneus longus tendon is most susceptible to injury at the cuboid notch owing to a change in its course as the tendon heads toward the first metatarsal base $[11,12]$. There have been several mechanisms proposed to explain the occurrence of a fracture of an os peroneum. The two most commonly proposed mechanisms are either direct trauma to the midfoot or violent dorsiflexion of the ankle and foot $[7,8,10]$. A less common mechanism is eversion against a supinated foot and ankle [6]. 
Clinically, the differential diagnosis of a lateral midfoot injury includes an injury to the lateral ligaments of the ankle, peroneus longus tenosynovitis, and peroneal tendon subluxation. Calcific tendinitis of the peroneus longus tendon, avulsion fractures of the cuboid bone, avulsions of the bony insertion of the peroneus brevis tendon, and calcaneal fractures can also be confused with a fractured os peroneum $[6,8]$. It is important to use multiple radiographic projections, including oblique views, to adequately examine the ossicle. If a fracture of the os peroneum is a consideration, MR imaging or ultrasound can be useful to further evaluate the peroneus longus tendon [10]. A ruptured peroneus longus tendon that is associated with a fracture of the os peroneum may be treated conservatively or surgically $[3,10]$.

Conflicts of interest The authors declare that they have no conflicts of interest.

\section{References}

1. Sobel M, Pavlov H, Geppert MJ, Thompson FM, DiCarlo EF, Davis WH. Painful os peroneum syndrome: a spectrum of conditions responsible for plantar lateral foot pain. Foot Ankle Int. 1994;15:112-24.
2. Coskun N, Yuksel M, Cevener M, Arican RY, Ozdemir H, Bircan O, et al. Incidence of accessory ossicles and sesamoid bones in the feet: a radiographic study of the Turkish subjects. Surg Radiol Anat. 2009;31:19-24.

3. Grisolia A. Fracture of the os peroneum: review of the literature and report of one case. Clin Orthop Relat Res. 1963;28:213-5.

4. Mains DB, Sullivan RC. Fracture of the os peroneum. A case report. J Bone Joint Surg Am. 1973;55:1529-30.

5. Tehranzadeh J, Stoll DA, Gabriele OM. Case report 271. Posterior migration of the os peroneum of the left foot, indicating a tear of the peroneal tendon. Skeletal Radiol. 1984;12:44-7.

6. Peacock KC, Resnick EJ, Thoder JJ. Fracture of the os peroneum with rupture of the peroneus longus tendon. Clin Orthop Relat Res. 1986;202:223-6.

7. Pessina R. Os peroneum fracture. A case report. Clin Orthop Relat Res. 1988;227:261-4.

8. Bianchi S, Abdelwahab IF, Tegaldo G. Fracture and posterior dislocation of the os peroneum associated with rupture of the peroneus longus tendon. Can Assoc Radiol J. 1991;42:340-4.

9. Truong DT, Dussault RG, Kaplan PA. Fracture of the os peroneum and rupture of the peroneus longus tendon as a complication of diabetic neuropathy. Skeletal Radiol. 1995;24:626-8.

10. Bashir WA, Lewis S, Cullen N, Connell DA. Os peroneum friction syndrome complicated by sesamoid fatigue fracture: a new radiological diagnosis? Case report and literature review. Skeletal Radiol. 2009;38:181-6.

11. Blitz NM, Nemes KK. Bilateral peroneus longus tendon rupture through a bipartite os peroneum. J Foot Ankle Surg. 2007;46:270-7.

12. Crain MR, el-Khoury GY. Stress fracture of the os peroneum. AJR Am J Roentgenol 1989;152:430. 